\title{
GERMINAÇÃO E ARMAZENAMENTO DE SEMENTES DE Nidularium innocentii (Lem.) ${ }^{1}$
}

\author{
CARLISE PEREIRA ${ }^{2}$, FRANCINE LORENA CUQUEL ${ }^{3}$, MARISTELA PANOBIANCO $^{3}$
}

\begin{abstract}
RESUMO - Em razão do crescente aumento do uso de bromélias no paisagismo brasileiro, elevada quantidade de plantas vem sendo retirada das matas de maneira não sustentável e, como consequência, algumas espécies já se encontram ameaçadas de extinção. A propagação sexuada pode ser uma alternativa para evitar o extrativismo de Nidularium innocentii, bromélia nativa do litoral do Estado do Paraná, que apresenta elevado potencial ornamental, razão pela qual é bastante procurada por extratores. Entretanto, estudos sobre a qualidade das sementes desta espécie ainda não foram desenvolvidos. $\mathrm{O}$ trabalho foi realizado com o objetivo de estabelecer a temperatura adequada para a condução do teste de germinação de sementes de Nidularium innoncetii e determinar condições favoráveis para o seu armazenamento. O estudo da germinação foi realizado com quatro subamostras de 25 sementes por tratamento, semeadas em caixas plásticas transparentes $(11,0$ x 11,0 × 3,5 cm), sobre duas folhas de papel mata borrão, umedecidas com água na quantidade de 2,5 vezes a massa do substrato, sendo testadas três temperaturas de incubação $\left(20^{\circ} \mathrm{C}, 25^{\circ} \mathrm{C}\right.$ e $\left.20-30^{\circ} \mathrm{C}\right)$. Para o armazenamento das sementes, foram utilizados dois tipos de embalagens (polietileno e papel), duas temperaturas $\left(4^{\circ} \mathrm{C}\right.$ e $\left.18{ }^{\circ} \mathrm{C}\right)$ e quatro períodos de armazenamento $(0,30,60$ e 90 dias). Determinou-se ainda o índice de velocidade de germinação e o peso de mil sementes. Pelos resultados obtidos concluiu-se que o teste de germinação pode ser conduzido utilizando-se as temperaturas de $20^{\circ} \mathrm{C}, 25^{\circ} \mathrm{C}$ ou $20-30{ }^{\circ} \mathrm{C}$; o armazenamento a $4{ }^{\circ} \mathrm{C}$, por um período de até 90 dias, é eficaz para a manutenção da viabilidade das sementes, podendo se empregar embalagens de polietileno ou papel.
\end{abstract}

Termos para indexação: análise de sementes, bromélia, floricultura, planta ornamental.

\section{GERMINATION AND STORAGE OF SEEDS OF THE BROMELIAD Nidularium innocentii (Lem.)}

\begin{abstract}
The use of bromeliads in Brazilian landscaping has recently increased, resulting in intense, non-sustainable, harvesting of wild bromeliads from native forests with the concomitant risk of extinction for some species. Sexual propagation may be an alternative to extractivism. The native bromeliad Nidularium innocentii occurs frequently in the Atlantic Forest area of the Brazilian state of Parana and has extensive ornamental potential, which has increased the interest of plant growers. Since there have been no previous studies on the quality of $N$. innocentii seeds we conducted experiments to establish the best storage conditions and germination temperature for this bromeliad. Seeds were stored in polyethylene or paper packages at $4{ }^{\circ} \mathrm{C}$ or $18{ }^{\circ} \mathrm{C}$ for four different storage periods $(0,30,60$ and 90 days), after which germination tests were performed at $20{ }^{\circ} \mathrm{C}, 25{ }^{\circ} \mathrm{C}$ and $20^{\circ} \mathrm{C}$ to $30^{\circ} \mathrm{C}$ in transparent plastic boxes $(11 \mathrm{~cm} \mathrm{x} 11 \mathrm{~cm} \mathrm{x} 3.5 \mathrm{~cm})$ lined
\end{abstract}

\footnotetext{
${ }^{1}$ Submetido em 04/11/2009. Aceito para publicação em 31/01/2010.

${ }^{2}$ Eng. Agr., M.Sc., Universidade Federal do Paraná, Rua dos Funcionários, 1540, Programa de Pós-graduação em Agronomia/ Produção Vegetal, Curitiba, PR, Brasil, E-mail: carlise.pereira@gmail.com.
}

\footnotetext{
${ }^{3}$ Eng. Agr., Dr., Prof. Adjunto, Universidade Federal do Paraná, Rua dos Funcionários, 1540, Programa de Pós-graduação em Agronomia/ Produção Vegetal, Curitiba, PR, Brasil, E-mail: francine@ufpr.bre maristela@ufpr. br.
} 
with two absorbent paper sheets moistened with water equivalent to 2.5 times the substrate mass. Four sub-samples of 25 seeds were used for each treatment. It was possible to conclude that germination testing may be conducted at $20^{\circ} \mathrm{C}, 25^{\circ} \mathrm{C}$ or $20-30{ }^{\circ} \mathrm{C}$. N. innocentii seeds can be stored for up to 90 days, with $4{ }^{\circ} \mathrm{C}$ appearing to be the best storage temperature for maintaining seed viability in polyethylene or paper packages.

Index terms: bromeliad, floriculture, ornamental plants, seed analysis.

\section{INTRODUÇÃO}

A Mata Atlântica, localizada ao longo do litoral brasileiro, é considerada um dos biomas mais ricos em biodiversidade, sendo de grande importância a sua preservação, uma vez que abriga espécies animais e vegetais que interagem entre si. Dentre as espécies que fazem parte deste bioma, destacam-se as bromélias, as quais possuem como característica a presença de um tanque formado pelo agrupamento de suas folhas, onde a água se acumula, servindo de micro habitat para muitas outras espécies (Müller e Marcondes, 2007).

Em razão do crescente aumento do uso de bromélias no paisagismo brasileiro, elevada quantidade de plantas vem sendo retirada das matas pela comunidade local, de maneira não sustentável, sendo comercializadas no mercado interno, o que tem acarretado a ameaça de extinção de algumas espécies (Barbosa, 2007; Rodrigues et al., 2007).

Embora apresentem grande potencial ornamental, poucas espécies de bromélias são produzidas em escala comercial, em razão da disponibilidade e fácil retirada do ambiente natural. Desta maneira, pouco tem sido feito para se estabelecer um sistema de cultivo de bromélias visando suprir a crescente demanda do mercado de plantas ornamentais, cujo comércio para a maioria das espécies é baseado no extrativismo (Anacleto, 2005; Negrelle et al., 2005). No litoral do Paraná, as bromélias oriundas do extrativismo apresentam baixa qualidade, uma vez que não recebem tratos culturais adequados; mesmo assim, representam um expressivo acréscimo financeiro para as famílias envolvidas (Anacleto, 2001).

Para que haja a preservação da biodiversidade, há necessidade do desenvolvimento de métodos para a produção de mudas de baixo impacto ambiental e reduzido custo, que preservem a diversidade genética das espécies, a fim de proporcionar aos extratores uma alternativa para propagação. Neste sentido, a multiplicação sexuada de bromélias pode ser promissora, havendo necessidade, no entanto, do conhecimento de fatores que influenciam a propagação, tais como: descrição do ponto de colheita de frutos; estabelecimento da melhor maneira de processamento dos mesmos; determinação de condições adequadas para a germinação e o armazenamento das sementes.

Para um grande número de espécies cultivadas existem recomendações para condução do teste de germinação nas Regras para Análise de Sementes (Brasil, 1992); entretanto, espécies nativas ornamentais carecem de informações. De acordo com Downs (1963) e Mercier \& Guerreiro Filho (1990), a germinação de sementes é um aspecto pouco estudado na reprodução de bromélias.

A família Bromeliaceae possui aproximadamente 3.000 espécies, distribuídas em 56 gêneros ( $\mathrm{SBBr}, 2008)$. De acordo com Leme \& Marigo (1993), grande parte das espécies ocorre no Brasil, sendo o gênero Nidularium, pertencente à subfamília Bromelioideae, exclusivamente brasileiro (Goff, 2006; Moreira et al., 2006). A espécie Nidularium innocentii (Lem.) é uma herbácea de pequeno porte, terrestre; sua inflorescência é em capítulo, medindo 12 a $18 \mathrm{~cm}$ (Figura 1); as brácteas primárias são verdes, com extremidade apical vermelha e margem levemente serrilhada em direção ao ápice; a bráctea floral é oval com o ápice agudo; as flores são sésseis, com pétalas brancas e sépalas esverdeadas, floresce do início de novembro a final de maio (Piacentini, 2006); o fruto é uma baga, de cor vermelho intenso quando maduro; as sementes são numerosas e pequenas, de aproximadamente $1,0 \mathrm{~mm}$ (Reitz, 1983; Morokawa, 2005).

Diante da crescente demanda de bromélias no paisagismo brasileiro e da falta de informações sobre sua propagação sexuada, este trabalho foi realizado com o objetivo de estabelecer a temperatura adequada para a condução do teste de germinação de sementes de Nidularium innoncetii e determinar condições favoráveis para o seu armazenamento. 


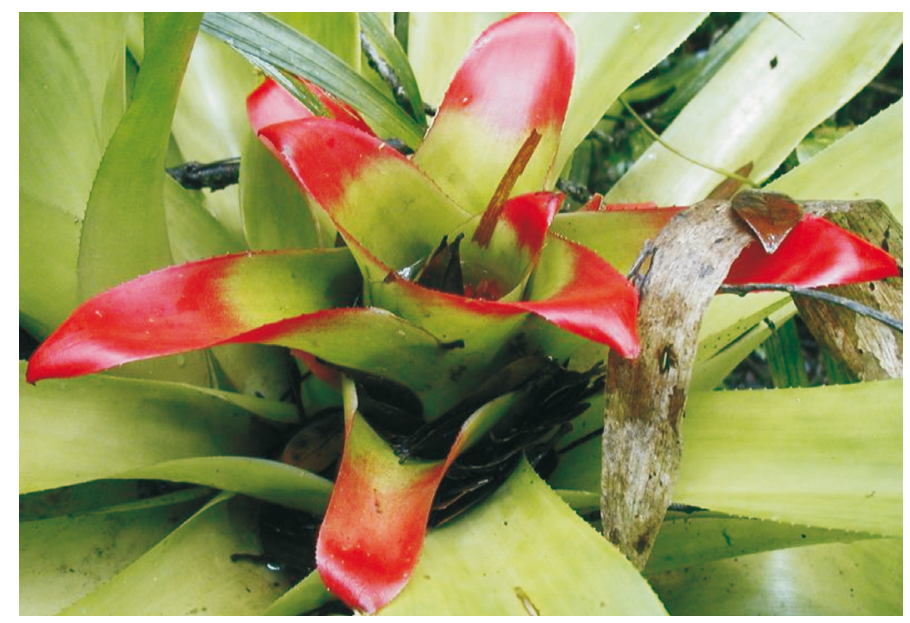

FIGURA 1. Inflorescência de Nidularium innocentii em condições naturais.

\section{MATERIAL E MÉTODOS}

Frutos de Nidularium innocentii foram coletados em área de sub-bosque localizada no município de Guaratuba ( $\left.25^{\circ} 86^{\prime} \mathrm{S}, 48^{\circ} 56^{\prime} \mathrm{W}\right)$, em abril de 2008 . Após a colheita, foram colocados em sacos de papel, identificados e levados a Laboratório de Análise de Sementes do Departamento de Fitotecnia e Fitossanitarismo, da Universidade Federal do Paraná, onde foi conduzida a pesquisa.

Os frutos colhidos apresentavam coloração avermelhada intensa, uniforme e brilhante; mediam em média $5,0 \mathrm{~cm}$ de comprimento e $1,0 \mathrm{~cm}$ de largura (Figura 2). As sementes foram extraídas dos frutos por pressão manual e receberam lavagem em água corrente, sob filtro de tecido. Após a lavagem, foram deixadas para secar em papel mata borrão por $72 \mathrm{~h}$, em ambiente controlado, a $18{ }^{\circ} \mathrm{C}$. A pré-secagem foi necessária para permitir a individualização das sementes envoltas em tecido mucilaginoso remanescente (Figura 3).

Foram testadas três temperaturas para realização do teste de germinação: duas constantes $\left(20^{\circ} \mathrm{C}\right.$ e $25^{\circ} \mathrm{C}$, na presença de luz) e uma alternada $\left(20-30{ }^{\circ} \mathrm{C}\right.$, com $16 \mathrm{~h}$ de escuro e $8 \mathrm{~h}$ de luz). Quatro subamostras de 25 sementes por tratamento foram colocadas para germinar em caixas plásticas transparentes $(11,0 \times 11,0 \times 3,5 \mathrm{~cm})$, sobre duas folhas de papel mata borrão, umedecidas com água na quantidade de 2,5 vezes a massa do substrato. Para as temperaturas constantes foram utilizados germinadores modelo Magelsdorf; para a temperatura alternada usou-se estufa incubadora tipo B.O.D.

A formação de plântula normal, com plúmula e raízes desenvolvidas, foi o critério estabelecido para a definição do primeiro dia de contagem das sementes germinadas. $\mathrm{O}$ Índice de Velocidade de Germinação - IVG foi calculado pela soma do número de sementes germinadas a cada dia e dividido pelo respectivo número de dias transcorrido após a semeadura, conforme Maguire (1962). Contagens diárias do número de plântulas normais foram realizadas com o objetivo de determinar o tempo mínimo necessário para a conclusão do teste de germinação. A determinação do encerramento do teste se deu quando o número de plantas normais tornou-se constante.

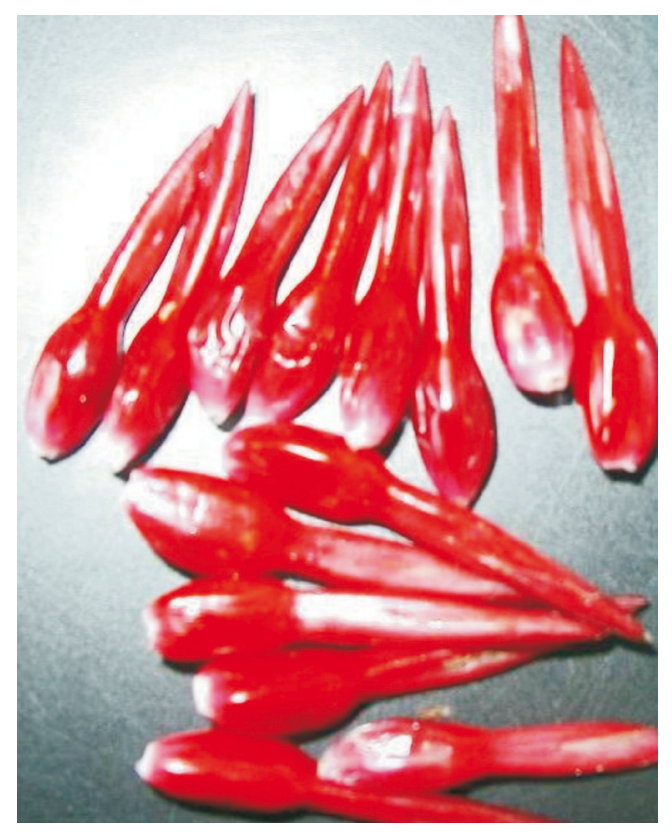

FIGURA 2. Frutos de Nidularium innocentii.

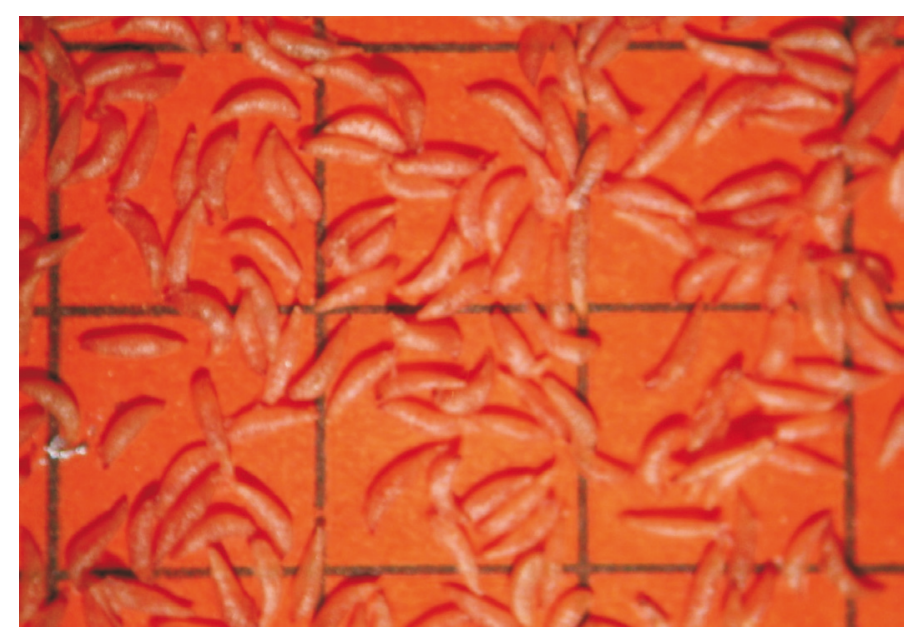

FIGURA 3. Sementes secas de Nidularium innocentii. Escala 1:2.000. 
A avaliação do peso de mil sementes foi conduzida com oito repetições de 100 sementes provenientes da porção "Semente Pura", de acordo com as prescrições estabelecidas nas Regras para Análise de Sementes (Brasil, 1992).

Para o estudo de armazenamento, foram testadas duas embalagens (polietileno e papel do tipo 'Kraft') e duas temperaturas: $4{ }^{\circ} \mathrm{C}$, umidade relativa de $90 \%$; e $18{ }^{\circ} \mathrm{C}$, umidade relativa de $73 \%$. A cada 30 dias, num total de 90 dias, foram retiradas amostras para a realização do teste de germinação, sendo conduzido com quatro subamostras de 25 sementes cada e colocadas para germinar em caixas plásticas transparentes $(11,0 \times 11,0 \times 3,5 \mathrm{~cm})$, sobre duas folhas de papel mata borrão, umedecidas com água na quantidade de 2,5 vezes a massa do substrato, em presença de luz, à temperatura de $20{ }^{\circ} \mathrm{C}$, em germinadores modelo Mangelsdorf. A contagem das sementes germinadas se deu aos 20 dias após a semeadura e foi encerrada aos 24 dias após o início do teste.

No experimento que avaliou o efeito das temperaturas sobre a germinação foi o utilizado delineamento estatístico inteiramente casualizado, efetuando-se as análises por comparação das médias pelo teste de Tukey, a $5 \%$ de probabilidade. $\mathrm{O}$ estudo de armazenamento foi instalado em arranjo fatorial $(2 \times 2 \times 4)$, representado por duas temperaturas, dois tipos de embalagens e quatro períodos de armazenamento. A análise destes dados foi efetuada por regressão. Utilizouse nos dois experimentos o programa estatístico ASSISTAT versão 7.5 Beta (Silva, 2008).

\section{RESULTADOS E DISCUSSÃO}

Pelos dados apresentados na Tabela 1, não houve diferença no poder germinativo das sementes nas três temperaturas testadas $\left(20^{\circ} \mathrm{C}, 25^{\circ} \mathrm{Ce} 20-30^{\circ} \mathrm{C}\right)$, provavelmente em razão das temperaturas estarem numa faixa próxima a do ecossistema natural das plantas. De acordo com o Instituto Meteorológico Simepar (2008), durante a realização da pesquisa, no local de coleta dos frutos, a temperatura variou de 16 a $25{ }^{\circ} \mathrm{C}$. A homogeneidade dos resultados no teste de germinação em diferentes temperaturas também foi encontrada por Tarré et al. (2007), que pesquisaram os gêneros de bromélias Encholirium e Dyckia e não observaram diferenças no poder germinativo das sementes quando testadas nas temperaturas de $20^{\circ} \mathrm{C}, 25^{\circ} \mathrm{C}$ e $30^{\circ} \mathrm{C}$. Da mesma forma, resultados semelhantes foram encontrados por Vieira et al. (2007) para a espécie Dyckia tuberosa (Bromeliaceae), a qual germinou em temperaturas de 20 a $40{ }^{\circ} \mathrm{C}$.

Pode-se observar também que as sementes apresentaram alta porcentagem de germinação (Tabela 1). Poder germinativo elevado também foi observado nas bromélias Aechmea beeriana e Aechemea distichantha, naturais da Amazônia Central e da Mata Atlântica, respectivamente, as quais apresentaram $100 \%$ de germinação em temperaturas na faixa de $15{ }^{\circ} \mathrm{C}$ a $35{ }^{\circ} \mathrm{C}$ (Mercier e Guerreiro Filho, 1990; Nara e Weber, 2002).

TABELA 1. Porcentagem de germinação e índice de velocidade de germinação (IVG) de sementes de Nidularium innocentii, em diferentes temperaturas.

\begin{tabular}{lcc}
\hline Temperatura & Germinação $(\%)$ & IVG \\
\hline $20{ }^{\circ} \mathrm{C}$ & $92 \mathrm{a}$ & $1,10 \mathrm{a}$ \\
$25{ }^{\circ} \mathrm{C}$ & $78 \mathrm{a}$ & $0,98 \mathrm{a}$ \\
$2030{ }^{\circ} \mathrm{C}$ & $90 \mathrm{a}$ & $1,08 \mathrm{a}$ \\
\hline $\mathrm{CV}(\%)$ & 16,13 & 15,01 \\
\hline
\end{tabular}

Médias seguidas da mesma letra minúscula na coluna não diferem entre si pelo teste de Tukey a $5 \%$ de probabilidade.

A alta porcentagem de germinação obtida na faixa de temperatura de 20 a $30^{\circ} \mathrm{C}$ evidencia que a espécie pode facilmente ser propagada em viveiros inseridos no próprio ecossistema da planta, sem a necessidade de controle de temperatura. Isto possivelmente seria uma alternativa para redução de custos na implantação de estruturas adequadas para a propagação, favorecendo a propagação de bromélias por sementes.

A espécie estudada apresentou porcentagens de germinação acima de $75 \%$ nas três temperaturas testadas; entretanto, em função da maior facilidade para realização do teste em temperaturas constantes, sugere-se a utilização das temperaturas de $20^{\circ} \mathrm{C}$ ou $25^{\circ} \mathrm{C}$ para a condução do teste de germinação.

O início da germinação das sementes ocorreu a partir do $10^{\circ}$ dia após a semeadura, quando foi verificado o início da protrusão da raiz primária. Entretanto, verificouse a formação de plântulas normais (Figura 4) somente no $20^{\circ}$ dia; após o $24^{\circ}$ o dia, o número de plantas normais foi constante. Observou-se que o Índice de Velocidade de Germinação (IVG) diminuiu com o acréscimo da temperatura sem haver, contudo, diferenças significativas entre as temperaturas (Tabela 1). $\mathrm{O}$ fato das sementes dessa bromélia levar 20 dias para produzir plântulas normais possivelmente está associado a algum mecanismo de dormência. O peso de mil sementes obtido foi de $2,137 \mathrm{~g}$.

Não foram observadas interações significativas entre os fatores (temperaturas, embalagens, períodos de 
armazenamento) avaliados durante o armazenamento. A germinação das sementes foi maior quando elas foram armazenadas na temperatura de $4{ }^{\circ} \mathrm{C}$ (Tabela 2); baixas temperaturas conservam melhor os componentes celulares, permitindo a disponibilização das reservas para a respiração da semente (Peterbauer \& Richter, 2001). Resultados semelhantes de maior conservação de sementes sob baixas temperaturas foram observados em Calliandra foliosa (Calil et al., 2007), onde o armazenamento em câmara fria $\left(5^{\circ} \mathrm{C}\right.$ e $80 \%$ de umidade relativa) foi benéfico para a manutenção da sua viabilidade.

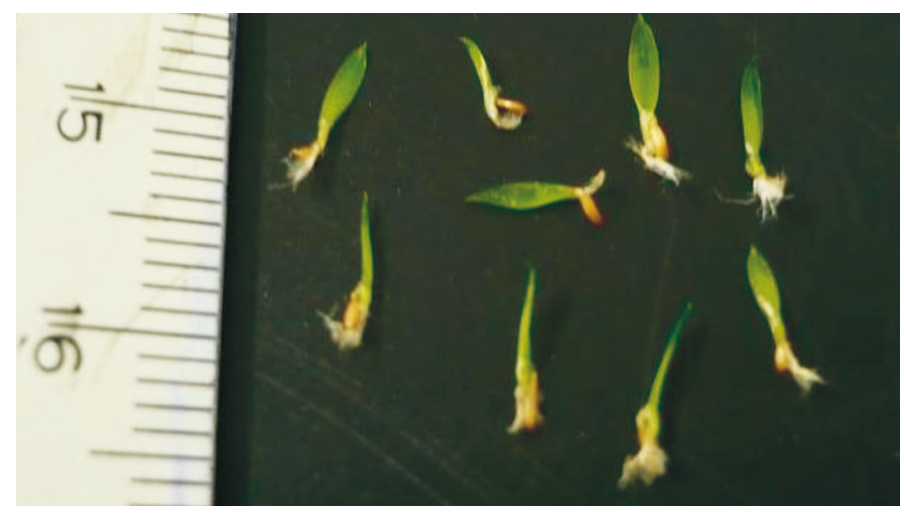

FIGURA 4. Plântulas normais de Nidularium innocentii.

TABELA 2. Germinação de sementes de Nidularium innocentii em diferentes temperaturas de armazenamento.

\begin{tabular}{lc}
\hline Temperatura $\left({ }^{\circ} \mathrm{C}\right)$ & Germinação $(\%)$ \\
\hline 4 & $91 \mathrm{a}$ \\
18 & $86 \mathrm{~b}$ \\
\hline DMS & 4,16
\end{tabular}

Médias seguidas da mesma letra minúscula na coluna não diferem entre si pelo teste de Tukey a $5 \%$ de probabilidade.

O tipo de embalagem utilizado não afetou a germinação das sementes armazenadas, demonstrando que é possível utilizar tanto embalagens de polietileno quanto de papel.

A porcentagem de germinação diminuiu ao longo do armazenamento (Figura 5), embora permanecesse com poder germinativo elevado após 90 dias (acima de 80\%). Isto indica que as sementes mantiveram sua viabilidade por três meses, o que pode ser benéfico para a produção de mudas via semente, uma vez que permite ao pequeno produtor fazer um planejamento da próxima semeadura, escalonando sua produção.

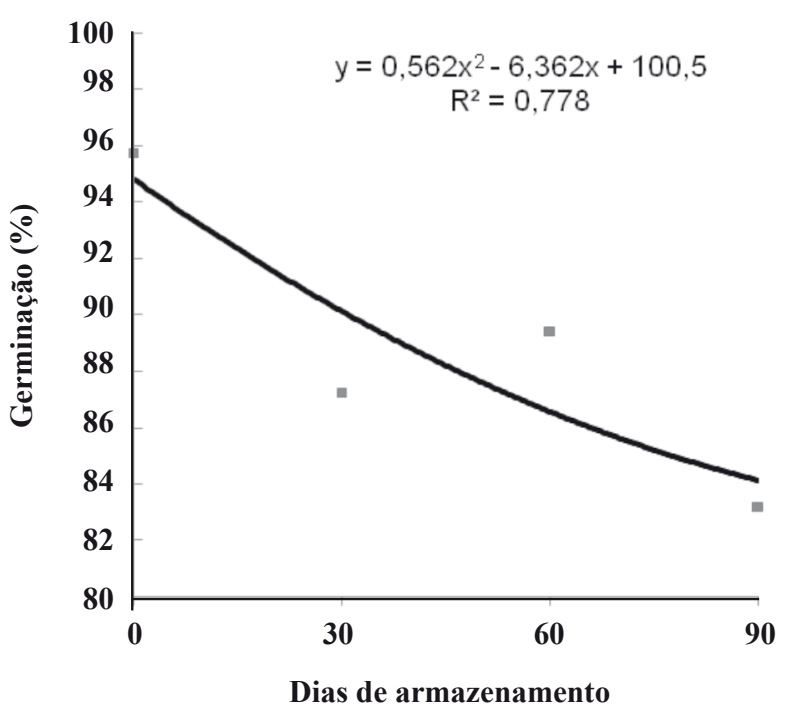

FIGURA 5. Porcentagem de germinação de sementes de Nidularium innocentii nos diversos períodos de armazenamento.

\section{CONCLUSÕES}

- O teste de germinação de sementes de $N$. innocentii pode ser conduzido nas temperaturas de $20^{\circ} \mathrm{C}, 25^{\circ} \mathrm{C}$ e $20-30^{\circ} \mathrm{C}$;

- O armazenamento a $4{ }^{\circ} \mathrm{C}$, por um período de até 90 dias, é eficaz para a manutenção da viabilidade das sementes de $N$. innocentii, tanto acondicionadas em embalagens de polietileno quanto de papel.

\section{REFERÊNCIAS}

ANACLETO, A. Cultivo de bromélias e plantas ornamentais. EMATER-PARANÁ. Guaratuba, 2001. 18p. Relatório Técnico.

ANACLETO, A. Germinação e crescimento clonal de Aechmea nudicaulis (L) Griseb (Bromeliaceae): subsídios à produção e extrativismo sustentável. 2005. 75f. Dissertação (Mestrado em Agronomia, Produção Vegetal) - Setor de Ciências Agrárias, Universidade Federal do Paraná, Curitiba. 
BARBOSA, G.C.V. Substrato e indutores de florescimento em bromélias ornamentais. 2007. 88f. Dissertação (Mestrado em Fitotecnia) - Universidade Federal de Viçosa, Viçosa.

BRASIL. Ministério da Agricultura e Reforma Agrária. Secretaria Nacional de Defesa Agropecuária. Departamento Nacional de Defesa Vegetal. Coordenação de Laboratório Vegetal. Regras para análise de sementes. Brasília, DF, 1992. 365p.

CALIL, A.C.; LEONHARDT, C.; SOUZA, L.S.; SILVA, V.S. Influência do armazenamento em câmara fria sobre a viabilidade de sementes de Calliandra foliosa Benth. (Leguminosae-Mimosoideae). Revista Brasileira de Biociências, v.5, supl. 1, p.774-776, 2007.

DOWNS, R.J. Photocontrol of germination of seeds of Bromeliaceae. Phyton, v.21, p.1-6, 1963.

GOFF, P. Nidularium cultural information. Disponível em: $\quad<$ http://bromeliads.home.att.net/Nidularium.htm $>$. Acesso em: 21 jun. 2008.

INSTITUTO METEOROLÓGICO SIMEPAR. Tecnologia e Informações Ambientais. Dados Metereológicos de Guaratuba. Guaratuba, 2008. 1 Cd-Rom.

LEME, E.M.C.; MARIGO, L.C. Bromeliads in the Brazilian wilderness ("Bromélias na natureza"). Rio de Janeiro: Marigo Comunicação Visual / Banco da Bahia, Brazil, p.184, 1993.

MAGUIRE, J.D. Speed of germination: aid in selection and evaluation for seedling emergence and vigour. Crop Science, v.2, n.2, p.176-177, 1962.

MERCIER, H.; GUERREIRO FILHO, O. Sexual propagation of some native bromeliads of Mata Atlântica: effect of light and temperature on germination. Hoehnea, v.17, p.19-26, 1990.

MOREIRA, B.A.; WANDERLEY, M G.; BARROS, M.A.V.C. Bromélias: importância ecológica e diversidade. Taxonomia e morfologia - Curso de Capacitação de Monitores. São Paulo: Instituto de Botânica, p.12, 2006.

MOROKAWA, R. Bromeliaceae do Parque Florestal do Rio da Onça - Matinhos, PR. 2005. Monografia (Bacharel em Ciências Biológicas) - Setor de Ciências Biológicas, Universidade Federal do Paraná, Curitiba.

MÜLLER, G.A.; MARCONDES, C.B. Immature mosquitoes (Diptera: Culicidae) on the bromeliad Nidularium innocentii in ombrophilous dense forest of Santa Catarina Island, Florianópolis, Santa Catarina State, southern Brazil. Revista Biotemas, v.20, n.2, p.27-31, 2007.

NARA, A.K.; WEBBER, A.C. Biologia floral e polinização de Aechmea beeriana (Bromeliaceae) em vegetação de baixio na Amazônia Central. Acta Amazônica, v.32, p.571588, 2002.

NEGRELLE, R.R.B.; ANACLETO, A.; MITCHEL, D. Local production and global markets: lessons for southern Brazil. In: "A future beneath the trees" International Symposium Proceedings, Victoria (BC, Canada), 2005.

PETERBAUER, T.; RICHTER, A. Biochemistry and physiology of raffinose family oligosaccharides and galactosyl cyclitols in seeds. Seed Science Research, v.11, p.185-197, 2001.

PIACENTINI, V. de Q. Relações entre floração de bromélias e uma comunidade de beija-flores numa área de Floresta Ombrófila Densa no Sul do Brasil. 2006. 39f. Dissertação (Mestrado em Ecologia e Conservação - Setor de Ciências Biológicas), Universidade Federal do Paraná, Curitiba, 2006.

REITZ, R. Bromeliáceas e a malária - bromélia endêmica. Itajaí: Flora Ilustrada Catarinense, p.808, 1983.

RODRIGUES, I.M.C.; FERREIRA, F.A.; GROSSI, J.A.S.; BARBOSA, J.G.; PAULA, C.C.; REIS, M. R. Ocorrência de plantas daninhas no cultivo de bromélias. Planta Daninha, v.25, n.4, p.727-733, 2007.

SBBr - SOCIEDADE BRASILEIRA DE BROMÉLIASSBB. Bromélias e a natureza. Disponível em: $<\mathrm{http}: / / \mathrm{www}$. bromelia.org.br>. Acesso em: 13 jul. 2008.

SILVA, F. de A. dos S. Programa estatístico, versão 7.5 (Beta), Campina Grande, Paraíba, 2008.

TARRÉ, E.; PIRES， B.B.M.; GUIMARÃES， A.P.M.; CARNEIRO, L.A.; FORZZA, R.C.; MASUR, E. Germinability after desiccation, storage and cryopreservation of seeds from endemic Encholirium Mart. ex Schult. \& Schult. f. and Dyckia Schult. \& Schult.f. species (Bromeliaceae). Acta Botanica Brasilica, v.21, n.4, p.777-783, 2007.

VIEIRA, D.C.M.; SOCOLOWSKI， F.; TAKAKI， M. Germinação de sementes de Dyckia tuberosa (Vell.) Beer (Bromeliaceae) sob diferentes temperaturas em luz e escuro. Revista Brasileira de Botânica, v.30, n.2, p.183-188, 2007. 